\title{
Relationally Aggressive Media Exposure and Children's Normative Beliefs: Does Parental Mediation Matter?
}

Jennifer Ruh Linder

Linfield College

Nicole E. Werner

Washington State University

Follow this and additional works at: https://digitalcommons.linfield.edu/psycfac_pubs

Part of the Child Psychology Commons, Developmental Psychology Commons, and the Television Commons

\section{DigitalCommons@Linfield Citation}

Linder, Jennifer Ruh and Werner, Nicole E., "Relationally Aggressive Media Exposure and Children's Normative Beliefs: Does Parental Mediation Matter?" (2012). Faculty Publications. Accepted Version. Submission 7.

https://digitalcommons.linfield.edu/psycfac_pubs/7

This Accepted Version is protected by copyright and/or related rights. It is brought to you for free via open access, courtesy of DigitalCommons@Linfield, with permission from the rights-holder(s). Your use of this Accepted Version must comply with the Terms of Use for material posted in DigitalCommons@Linfield, or with other stated terms (such as a Creative Commons license) indicated in the record and/or on the work itself. For more information, or if you have questions about permitted uses, please contact digitalcommons@linfield.edu. 
Relationally Aggressive Media Exposure and Children's Normative Beliefs: Does Parental Mediation Matter?

Jennifer Ruh Linder

Linfield College

Nicole E. Werner

Washington State University 


\begin{abstract}
Research indicates that relationally aggressive media exposure is positively associated with relational aggression in children. Theories of media effects suggest that these associations may be mediated by aggressive cognitions. Although parental mediation can attenuate the effects of violent media, it is unknown whether there are similar benefits of parental mediation of relationally aggressive media. The current study examined concurrent and longitudinal associations between relationally aggressive television and movie exposure and normative beliefs about relational aggression, and whether parental mediation moderates these associations. Participants were 103 children (50\% female) in grades 3-6 and their parents. The following year, 48 children (52\% female) were again assessed. Relationally aggressive media exposure predicted concurrent relational aggression norms, even after controlling for physically aggressive media exposure and physical aggression norms. Relationally aggressive television and movie exposure predicted greater subsequent approval of relational aggression only among children whose parents engaged in low levels of active mediation.
\end{abstract}

KEYWORDS: normative beliefs; parental active mediation; relationally aggressive media 
Relationally Aggressive Media Exposure and Children's Normative Beliefs: Does Parental Mediation Matter?

In recent years there has been increased interest in the negative effects of relational aggression in the media on viewers. Relational aggression refers to behaviors that inflict harm through the manipulation of relationships. This form of aggression is distinct from physical aggression and includes behaviors such as spreading rumors, social exclusion, and threats to withdraw love or friendship (Crick \& Grotpeter, 1995). Existing content analyses indicate that relational aggression, and the related behaviors of indirect and social aggression, are prevalent in television programming and movies, and are often presented in ways that facilitate learning of relationally aggressive behaviors and beliefs supportive of this subtype of aggression (Coyne \& Archer, 2004; Linder \& Gentile, 2009; Linder \& Lyle, 2011). In addition, correlational and experimental studies provide evidence of links between relationally aggressive media exposure and relationally aggressive behavior among children, adolescents, and adults, and that the effects of relationally aggressive media exposure differ from those of violent media exposure (Coyne \& Archer, 2005; Coyne, Archer, \& Eslea, 2004; Coyne et al., 2008; 2011; Linder \& Gentile, 2009). Less is known about the effects of relationally aggressive media exposure on aggressive cognitions, which may be an important mediator of media effects on aggression. The first goal of this study was to examine concurrent and longitudinal associations between relationally aggressive media exposure and children's normative beliefs about relational aggression. Additionally, there is a need for research that investigates ways to mitigate the negative effects of relationally aggressive media exposure. Therefore the second goal of the study was to investigate if active parental mediation of media, as indicated by discussion of media content, moderates these associations. 


\section{Prevalence and Effects of Relational Aggression in Television and Movies}

Recent content analyses indicate that depictions of relational aggression are prevalent on television in a variety of genres (Coyne \& Archer, 2004; Coyne, Robinson, \& Nelson, 2010; Linder \& Gentile, 2009). Although less is known about the prevalence of relational aggression in movies, Coyne and Whitehead (2008) found that relational aggression occurs in animated Disney films at similar rates as has been found on television. Televised relational aggression is likely to be portrayed as justified, rewarded, and used by attractive characters (Coyne \& Archer, 2004; Linder \& Lyle, 2011), which social learning theories suggest increases the likelihood that exposure will result in increased viewer aggression (Bandura, 1965; 1986; Berkowitz \& Powers, 1979; Hogben, 1998; Wilson et al., 1998). Indeed, correlational and experimental studies indicate that exposure to televised relational aggression predicts higher levels of relational aggression among viewers, including children (Coyne et al., 2004; Coyne \& Archer, 2005; Coyne et al., 2008; 2011; Linder \& Gentile, 2009). One limitation of the existing research is that there is a paucity of studies, particularly longitudinal studies, investigating possible mechanisms that account for the associations between relationally aggressive media exposure and behavior. The current study aimed to address this gap in the field by focusing on children's normative beliefs about relational aggression.

\section{Theoretical Models of Media Effects and Aggression}

The General Aggression Model (GAM; Anderson \& Bushman, 2002) is a theoretical model that explains the mechanisms by which media violence exposure increases aggressive behavior. Long-term effects of aggressive media exposure include the development of aggressive scripts, beliefs, and attitudes, which in turn increase the likelihood of aggressive behavior when combined with certain situational variables. There is substantial empirical 
support for this model when applied to physically aggressive media exposure (for a review, see Anderson \& Bushman, 2001). Regarding cognitions, exposure to violent television and video games has been shown to increase hostile thoughts, as well as lead to more favorable attitudes toward aggression (for reviews, see Anderson et al., 2010; Bushman \& Huesmann, 2001; Murray, 2008). Violent media exposure may also be associated with changes in cognitions about relational aggression over time. A longitudinal study by Gentile and colleagues (Gentile, Coyne, \& Walsh, 2011) with a sample of third to fifth-grade children demonstrated that exposure to media violence was associated with increased relational hostile attribution bias 5 months later.

Researchers have begun to apply the GAM to the study of relationally aggressive media effects. For example, Coyne, Linder, Nelson, and Gentile (in press) found that women exposed to a brief video clip of relational aggression exhibited activation of relationally aggressive scripts, as indicated by interference in processing relationally aggressive words in an emotional Stroop task. These results suggest that the same cognitive mechanisms that account for shortterm media violence effects operate when viewers are exposed to relationally aggressive media. We are unaware of any research that has examined the mechanisms outlined by the GAM regarding the long-term cumulative effects of relationally aggressive media exposure, namely the development of aggressive beliefs and attitudes. Additionally, we are not aware of any longitudinal research on relationally aggressive media exposure, thereby limiting our understanding of the long-term effects of relationally aggressive media exposure.

Consistent with the GAM, other theories of both aggression and media effects suggest that beliefs and attitudes about relational aggression can be acquired through the mass media, and that these beliefs contribute to individual differences in aggressive behavior. For example, cultivation theory (Gerbner, Gross, Morgan, \& Signorielli, 1994) posits that cumulative exposure 
to media shapes viewers' perceptions of reality. As a result, heavy viewers of television develop beliefs and attitudes about issues such as gender roles (Signorielli \& Lears, 1992) and crime (Gerbner et al., 2004) that are consistent with worldviews conveyed by media portrayals. Middle childhood is a developmental period in which children may be especially vulnerable to cultivation effects, because they are in the process of developing their social norms and beliefs (Gentile \& Sesma, 2003). Exposure to media therefore may contribute to the development of beliefs about the prevalence, effectiveness, and acceptability of a variety of social behaviors, including relational aggression. Social information processing (SIP) models of aggression also emphasize the importance of cognitive factors, such as attitudes, attributions, and decisionmaking processes in individual differences in aggression (Crick \& Dodge, 1994; Huesmann, 1988). Two decades of research has shown that aggressive children have hostile schemas and attitudes supportive of aggression (e.g., Burks, Laird, Dodge, Pettit, \& Price, 1999; Huesmann \& Guerra, 1997), and they engage in moment-to-moment processing of social cues in ways that increase the likelihood of using aggression (see Crick \& Dodge, 1994; Orobio de Castro et al., 2002, for reviews).

One important type of aggressive cognition is normative beliefs, which refer to an individual's generalized beliefs about the legitimacy or normative nature of aggressive behavior (Huesmann \& Guerra, 1997). Numerous studies have shown that children who view overt aggression as an acceptable response are more aggressive (e.g., Henry et al.,, 2000; Zelli, Dodge, Lochman, \& Laird, 1999). More recently, research by Werner and others has established that holding beliefs supportive of relational aggression is associated with more frequent use of relational aggression (Murray-Close, Crick, \& Galotti, 2006; Werner \& Hill, 2010; Werner \& Nixon, 2005). Although only a few studies have explored the origins of children's normative 
beliefs about aggression, theoretical and empirical evidence suggests that normative beliefs develop as a result of observations of and interactions with socializing agents, including parents (e.g., Nix, Pinderhughes, Dodge, Bates, Pettit, \& McFayden-Ketchum, 1999) peers (Werner \& Hill, 2010), and the media (for a review, see Kirsh, 2010).

In sum, there is both theoretical and empirical support to suggest that an important mechanism by which relationally aggressive media exposure may contribute to relationally aggressive behavior is by influencing normative beliefs about this subtype of aggression. Therefore, an important aim of the current study was to examine associations between relationally aggressive television and movie exposure and normative beliefs about relational aggression.

\section{Parental Active Mediation and Aggressive Media Exposure Effects}

Past research indicates that one important moderator of the effects of media exposure on children is parental mediation of media. Parental mediation is a broad term that includes rules surrounding media use (including time spent with media and content restrictions), as well as strategies that encourage the critical appraisal of media. Parental mediation is generally linked with positive outcomes for child viewers, but specific effects of parental mediation depend on the type of mediation used. Although a variety of labels have been used to describe subtypes of mediation, researchers have primarily focused on three different types of parental mediationrestrictive, coviewing, and active (e.g., Nathanson, 1999; Valkenburg, Krcmar, Peeters, \& Marseille, 1999). Restrictive mediation refers to rules about content and amount of viewing; coviewing occurs when an adult watching television and movies with children; and active mediation refers to discussions about media content. Active mediation has been conceptualized to include a variety of discussion-based behaviors by parents, including evaluative statements 
about the acceptability of behaviors portrayed on television, conversations about the technical aspects of television, and promotion of critical viewing that discounts the reality of television (see Nathanson, 2001). Of the three types of mediation, active mediation has been more consistently associated with positive outcomes for child viewers, such as increased skepticism of television content (e.g., Austin, 1993) reduced aggression (e.g., Nathanson, 1999), and increased resistance to advertisements (Buijzen \& Valkenburg, 2005).

Active mediation has also been shown to moderate the effect of physically aggressive media on children's cognitions. Experimental research with children has revealed that exposure to negative evaluative comments from adults about televised violence during viewing is associated with reductions in children's perceptions of the normative nature and acceptability of physical aggression (Corder-Bolz, 1980). Effects of some types of active mediation appear to be stronger for boys (Nathanson \& Cantor, 2000) and for older school-aged children than for younger children or older youth (Corder-Bolz, 1980; Nathanson \& Yang, 2003). Correlational research focusing on parental mediation has found similar benefits of active mediation. Nathanson (1999) found that parental active mediation of violent television was negatively associated with aggressive attitudes and behaviors in a sample of children in grades 2 to 6 . Notably, parental mediation exerted its influence on reduced aggression by modifying children's perceptions about violent content they viewed. Specifically, active mediation of violent media content was negatively associated with children's perceived importance of violent television.

In light of this research, it seems likely that the development of beliefs and attitudes about relational aggression may also be influenced by parental active mediation of media. Parentchild discussions about relationally aggressive media portrayals may alter how children perceive media depictions of relational aggression, and therefore how these depictions contribute to their 
normative beliefs about relational aggression. Such discussions between parents and children may alter children's norms by making children more skeptical of the realism of media portrayals of relational aggression, altering the importance they assign to media portrayals of relational aggression, and/or affording the opportunity for parents to convey their own beliefs about the acceptability of relational aggression. Parental attempts at active mediation of aggressive media content may be particularly important for school-aged children, given that their beliefs about relational and physical aggression have been shown to change between middle childhood and early adolescence (Werner \& Hill, 2010).

\section{The Current Study}

The current study aims to increase our understanding of the role of media in the development of relationally aggressive beliefs by examining concurrent and longitudinal associations between relationally aggressive television and movie exposure and normative beliefs about relational aggression in a sample of school-aged children. Additionally, we examined whether parental active mediation of television and movie content would mitigate these exposure effects. Based on existing content analyses of relationally aggressive media portrayals and theoretical models of media effects, the first hypothesis was that there would a positive association between exposure to relationally aggressive media (i.e., television and movies) and concurrent normative beliefs that reflect acceptance of relational aggression, as well as normative beliefs assessed one year later. Furthermore, we expected that there would be a unique contribution of relationally aggressive media exposure in the prediction of normative beliefs, above and beyond the contribution of exposure to physically aggressive media and beliefs about physical aggression. Although some studies have found gender differences in mean levels of relational aggression, a recent meta-analysis showed negligible gender differences 
(Card, Stucky, Sawalani, \& Little, 2008). In addition, available studies of relationally aggressive media, and of normative beliefs about relational aggression, have typically not found evidence of gender-specific effects (Coyne et. al, 2004; Coyne et al., 2011; Werner \& Hill, 2010; Werner \& Nixon, 2005). For these reasons, we did not expect to find gender differences in the associations of relationally aggressive media exposure and relational aggression. We did, however, control for child gender in our analyses.

Based on empirical research regarding parental active mediation of violent media as well as the role of parent-child discussions in the development of relational aggression in children (Werner, Lyle, Eaton, \& Tseng, under review), our second hypothesis was that parental discussion of media content would moderate the effects of relationally aggressive media exposure on normative beliefs. Specifically, we hypothesized that active mediation would mitigate the association between relationally aggressive media exposure and both concurrent and subsequent acceptance of relational aggression.

\section{Method}

\section{Participants}

Participants included $3^{\text {rd }}-6^{\text {th }}$ grade children, their primary caregivers and their teachers. Children were drawn from a larger school-based study of social development conducted in three elementary schools and one middle school in a small school district in the Northwest $(\mathrm{N}=486)$. We mailed letters home with all children in the school-based study inviting interested families to participate in a smaller home-based investigation. A total of 103 of these children (52 females) and their primary caregivers $(\mathrm{N}=97$ mothers; $\mathrm{N}=6$ fathers $)$ completed surveys about aggressive media exposure and parental mediation of media for the present study. The consent rate for the family study was $21 \%$. Children were approximately evenly distributed across grades $\left(373^{\text {rd }}\right.$ 
graders, $214^{\text {th }}$ graders, $245^{\text {th }}$ graders and $216^{\text {th }}$ graders). Children's parents were highly educated, with $79 \%$ of mothers and $74 \%$ of fathers having earned a Bachelor's degree or higher. Seventy percent of mothers were married, 11\% were divorced (not remarried or cohabitating), and the remaining mothers reported another family configuration (widowed, single-parent, cohabitating parent) or did not provide information about marital status. The ethnic makeup of this particular sample was $80 \%$ and $74 \%$ White (for mothers and children, respectively), $9.5 \%$ and $8 \%$ Asian, and $10.5 \%$ and $18 \%$ Other.

We compared children in the current study ("family sample") with the larger schoolbased sample on self- and teacher-ratings of child behavior and adjustment (i.e., achievement motivation, grades, aggression, prosocial behavior, normative beliefs about aggression, and emotional regulation) to evaluate selection effects. No significant differences were found. Teacher ratings of parent involvement in the school also did not differ between groups. Therefore, for child behavior and parent involvement, the family sample was very similar to the school-based sample.

A total of 50 children completed an in-school survey about normative beliefs the following year (Time 2). The number of participants we were able to follow was small due to changes in school administration which prohibited us from collecting data in the middle school during the follow up assessment. Nonetheless, the longitudinal sample did not differ from the Time 1 sample in gender composition, nor on mother-reports of monitoring, or child-reports of aggressive media exposure and normative beliefs about relational aggression. Participants in the longitudinal sample were less approving of physical aggression compared to children in the Time 1 only sample, however, $t(101)=2.13, p=.04$.

\section{Procedures}


Data were collected in two locations: the child's classroom and the child's home. All adult participants provided written informed consent, and child participants provided written and verbal assent prior to data collection in both locations. For the school-based data collection, children completed a battery of surveys measuring social behavior, attitudes and school adjustment in a single session that took place during school hours in the early spring. These procedures were identical at both the initial assessment (Time 1) and the follow-up assessment (Time 2). Research assistants read instructions and survey items aloud while children followed along and marked answers in their own survey packets. At the initial assessment only (i.e., during the spring and summer of the same academic year), mothers, fathers, and target children took part in a home-based session. During 1-2 hour home visits, children and parents completed surveys individually under the guidance of two female research assistants (one assigned to parent(s) and the other designated for the child). Children in grades 3 and 4 were read each survey item aloud while they followed along and marked answers in their own survey packets. Parents were given instructions for each survey, and they were instructed to complete surveys without consulting their spouse. Research assistants were available to answer any questions that arose during survey completion. Families were paid $\$ 50$ for participation in the home interview and children were given small rewards (e.g., stickers, pencils).

\section{Measures}

Child normative beliefs about aggression. Normative beliefs about relational and physical aggression were assessed at Time 1 and Time 2 with items used in prior research (Huesmann \& Guerra, 1997; Werner \& Nixon, 2005). Participants rated the acceptability of aggressive behaviors on 5-point Likert scales ranging from 1 (no!) to 5 (yes!). Higher scores reflected greater approval of aggression. Normative beliefs about relational aggression were 
assessed with three items (e.g., "In general, it is OK to tell your friends not to be friends with someone you don't like'’). Beliefs about physical aggression were assessed with four items (e.g., "In general, it is OK to hit other people"'). We conducted a confirmatory factor analysis using MPlus 4.21 (Muthén \& Muthén, 1998-2007) on the seven normative belief items using the larger school-based sample of children. A one-factor model yielded good fit, $\chi^{2}(14)=72.0, p<.001$; $\mathrm{RMSEA}=.08, \mathrm{SRMR}=.04, \mathrm{CFI}=.97$. However, a two-factor model fit the data significantly better, $\left.\chi^{2} \operatorname{diff}(1)=\right) 46.83, p<.001$. The final model provided an excellent fit to the data, $\chi^{2}(13)=$ $25.17, \mathrm{p}=.02 ; \mathrm{RMSEA}=.04, \mathrm{SRMR}=.02, \mathrm{CFI}=.99$. In the current sample, the beliefs about relational aggression and beliefs about physical aggression scales demonstrated acceptable reliability ( $\alpha \mathrm{s}=.64$ and .87 , respectively).

Child aggressive television and movie exposure. We measured children's aggressive media exposure using a slightly revised version of the General Media Habits Questionnaire Child Version (Anderson, Gentile, \& Buckley, 2007; Gentile, Lynch, Linder, \& Walsh, 2004). Participants first listed their favorite television show and movie, and then they rated how frequently they viewed each on a scale from 1 (I almost never watch this show / movie) to 5 (almost every day). With respect to television shows, the majority of participants mentioned cartoons (33\%) and sitcoms (23\%). Children's favorite movies were distributed across several genres, with the majority listing animated movies (20\%), action adventures (16\%), and comedies (15\%). Industry ratings were available for $75 \%$ of the listed movies; of these, $15 \%$ were rated $\mathrm{G}$, $38 \%$ were rated $\mathrm{PG}$, and $26 \%$ were rated $\mathrm{PG}-13$ or higher. Children rated the frequency with which characters in the show / movie displayed specific forms of aggression on a 4-point scale (1 $=$ never and $4=$ almost all the time). Relationally aggressive behavior was assessed with the item, "How often do characters give others the silent treatment or spread rumors about others?", 
and physically aggressive behavior was measured by a new item added for the purpose of this study, "How often do characters in this show hit, kick, or punch others?" Although these items do not assess all relationally and physically aggressive behaviors, they represent prototypical exemplars of these forms of aggression that have been used in past research (e.g., Linder \& Gentile, 2009). We examined the validity of these ratings by correlating children's ratings with the "violence" rating from the Common Sense Media website (commonsensemedia.org). Child reports of physical aggression in their favorite shows and movies were significantly, positively correlated with the independent violence ratings: $r(75)=.59, p<.001$ for television, and $r(86)=$ $.30, p<.01$ for movies. Although independent ratings are not currently available for relationally aggressive content, these correlations for violent content suggest that children are capable of evaluating media aggression.

Final exposure variables were created by multiplying the frequency of viewing by the aggressive content, and then averaging across the favorite TV show and favorite movie, thus yielding two scores for each participant: relationally aggressive media exposure and physically aggressive media exposure. This approach to measuring media violence exposure has been used reliably with children and adults (e.g., Anderson \& Dill, 2000; Gentile et al., 2004).

Active parental mediation of media. We operationalized active mediation as parental discussion about media content. We opted for this broad definition in order to capture any number of parent-child communications about media content that previous research has labeled as active mediation. We collected information about parental mediation of children's media usage from target children and their primary caregiver (in most cases, this was the child's mother). As a part of a structured interview about family technology use during the home interviews, mothers responded to two questions: "How often do you talk with your child about 
the TV shows he/she watches?" and "How often do you talk with your child about the movies or videos he/she watches?". Both items were rated on a 5-point scale from 1 (never) to 5 (always). Items were averaged to obtain a score for parental mediation of children's media use.

In 5 families, fathers were the primary caregiver and thus completed the technology interview, and in 1 family, only information from the target child was available. In these cases where mother-reports of mediation were unavailable, we substituted the average score across available informants of mediation. To determine the equivalence of this substitution, we compared scores for parental mediation in families with mother-report data $(\mathrm{N}=97)$ and those without mother-report data $(\mathrm{N}=6)$ and found no difference, $t(103)=1.32, p=.19$.

\section{Results}

We first examined the distribution of all study variables and found that children's physical aggression norms were kurtotic at Time 1 and Time 2. We computed log, arcsine and square root transformations on these variables; however none resulted in a significantly improved distribution. For ease of interpretation, we retained the untransformed variables for analyses. As can be seen in Table 1, preliminary analyses (i.e., correlations) showed that boys reported greater exposure to physically aggressive media exposure, and they also were more approving of relational aggression at Time 1. Children in higher grades were more approving of physical aggression at Time 1 . We thus controlled for child gender and grade in our primary analyses. Correlations also showed that children who reported higher exposure to relationally aggressive media were also exposed to more physically aggressive media, and children's approval of relational aggression and physical aggression were positively associated at Time 1 . 
To test our hypotheses regarding concurrent and longitudinal associations between relationally aggressive media exposure and normative beliefs about relational aggression, we computed two multiple regression models predicting normative beliefs about relational aggression at Time 1 and Time 2, respectively. In both models, we entered control variables at step 1: child gender, grade, physically aggressive media exposure, and physical aggression norms. We included the latter two control variables so that any significant effect of relationally aggressive media exposure on relational aggression norms would be unique to this subtype of aggression. At step 2 we added relationally aggressive media exposure and parental discussion about media, and in the third step, their interaction, to test our moderation hypothesis. The only difference between the concurrent and longitudinal models was that the latter model included Time 1 relational aggression norms (to control for the stability in normative beliefs during middle childhood) and Time 2 physical aggression norms (to control for shared variance between relational and physical aggression norms) in step 1.

Table 2 shows the results of our concurrent regression model. The final model was highly significant, $F(7,102)=9.11, \mathrm{p}<.001$. As expected, children who were more approving of physical aggression were also more approving of relational aggression, $t(102)=6.00, p<$ .001 . The only other significant predictor of relational aggression norms was exposure to relationally aggressive media, $t(102)=2.40, p=.02$. Thus, children who watched programming that contained frequent depiction of relationally aggressive behaviors between characters were more approving of relational aggression at the initial assessment. Parental mediation of media did not explain a significant amount of variance in children's normative beliefs about relational aggression, nor did it moderate the association of relationally aggressive media exposure on relational aggression norms. 


\section{Insert Table 2 about here}

Table 3 shows the results of the regression model predicting Time 2 relational aggression norms. The final model was highly significant, $F(8,49)=5.37, \mathrm{p}<.001$. Normative beliefs about relational aggression demonstrated moderate stability over the course of one year, as indicated by the significant univariate effect of Time 1 relational aggression norms, $t(49)=2.07$, $p=.05$. Children in higher grades were also more approving of relational aggression at Time $2, t$ $(49)=2.66, p=.01$. Importantly, exposure to relationally aggressive media at Time 1 predicted greater approval of relational aggression one year later, $t(49)=3.74, p=.001$. The interaction of relationally aggressive media exposure and parental discussion about media was also significant, $t(49)=-2.07, p=.01$. We followed up this interaction by re-computing the regression model separately for groups of children high and low on parental discussion of media (using a median split). As can be seen in Figure 1, the effect of relationally aggressive media exposure was significant for children whose primary caregivers engaged in low levels of mediation of media, $t$ $(21)=2.57, p=.02$, but not for those whose caregivers engaged in high levels of mediation, $t$ $(27)=1.34, p=.20$.

Insert Table 3 and Figure 1 about here

\section{Discussion}

The current study examined the impact of relationally aggressive media exposure on normative beliefs about relational aggression in a sample of school-aged children, and the role of parental active mediation of media in the concurrent and prospective associations of media exposure and approval of aggression. Given the high prevalence of depictions of relational aggression in the media and the demonstrated adverse associations of relational aggression on social-psychological adjustment, research on the mechanisms through which relational 
aggression develops is greatly needed. To our knowledge, our findings provide the first evidence that children who are consume high levels of relationally aggressive television and movies become increasingly approving of relationally aggressive behaviors over time. Importantly, though, this was only true for children whose parents engaged in low levels of active mediation.

The first hypothesis, that exposure to relationally aggressive media would be associated with norms that reflected greater acceptance of relational aggression, was supported by the data. Both concurrently and longitudinally, children's reports of relationally aggressive media exposure were positively associated with greater acceptance of relational aggression. These associations remained even after controlling for earlier relational norms, physical aggression norms, and physically aggressive media exposure. This suggests that the effects of aggressive media on attitudes and beliefs are specific to the subtype of aggression viewed. That is, normative beliefs about relational aggression are uniquely predicted by viewing relationally aggressive media, not by other forms of media aggression. Although there is ample evidence that exposure to violent media increases aggressive cognitions (for review, see Anderson et al., 2010), this is the first study we are aware of that has demonstrated a similar link between relationally aggressive media exposure and cognitions about relational aggression. Investigations of normative beliefs and aggressive behavior have also demonstrated specificity (see Werner \& Hill, 2010; Werner \& Nixon, 2005). Together, these findings suggest that children who consume media with frequent depictions of relational aggression are at heightened risk for engaging in relational aggression, but not necessarily other forms of aggression.

The way in which relational aggression is typically portrayed on television may account for its negative influence on children's normative beliefs. Content analyses of relational aggression on television indicate that relational aggression is often used by attractive characters, 
and is often rewarded and depicted as justified (Coyne \& Archer, 2004; Linder \& Lyle, in press). In light of this research, it is not surprising that exposure to relationally aggressive media was associated with more accepting norms about relational aggression in the current sample. The frequency of televised acts of relational aggression, particularly between friends and family members (Coyne \& Archer, 2004) might also contribute to perceptions that relational aggression is normative in close relationships.

These findings are notable because media effects models, in particular the GAM, posit that cognitions about aggression are an important mediator of the effects of aggressive media exposure. Additionally, research on both physical and relational aggression provides evidence that the development of aggressive scripts and beliefs that aggression is normative and acceptable is associated with increased aggressive behavior (e.g., Huesmann \& Guerra, 1997; Werner \& Hill, 2010). Therefore, it is likely that normative beliefs may be a mediator of the effects of relationally aggressive media on behavior. Future research is needed to determine whether media effects on relational aggression exert their influence via children's normative beliefs or other social-cognitive mechanisms.

The second hypothesis was that active parental mediation, in the form of parent-child discussions about media content, would mitigate the association between relationally aggressive television and movie exposure and both concurrent and subsequent norms about relational aggression. Although caution should be used in interpreting the findings due to the small sample size, this hypothesis was supported in our longitudinal subsample. For children whose parents engaged in low levels of discussion about media content, relationally aggressive media exposure was associated with more accepting norms about relational aggression one year later. In contrast, for children whose parents engaged in high levels of discussion about media content, 
there was no significant association between relationally aggressive media exposure and subsequent relational aggression norms.

These findings suggest a protective effect of parents' discussions with children about media content on children's' vulnerability to negative effects of relationally aggressive media exposure that may only emerge over time. That is, it may be that parent-child discussions about media do not immediately impact the children's relational norms, but rather the effects of such discussions are gradually incorporated into children's developing normative beliefs.

Alternatively (or in addition), discussions with parents about media content may provide children with critical viewing skills that increase children's skepticism of the accuracy of media portrayals of relational aggression. It may take some time before the effects of this increased resistance to media messages are reflected in children's normative beliefs. This latter suggestion is consistent with the results of a recent media violence intervention study with early adolescents by Moller and colleagues (Moller, Krahé, Busching, \& Krasue, 2011). This 12-month longitudinal study found that the effects of a 5-week school-based intervention that included the development of critical viewing skills of media violence were mediated by a reduction in normative acceptance of both physical and relational aggression. The post-intervention assessment of normative beliefs was conducted 7 months after the completion of the intervention, suggesting that the effects of the intervention on normative beliefs about relational aggression persisted over time.

Although this study is the first we are aware of to document the benefits of active parental mediation of media for altering the effects of relationally aggressive media, there are many unanswered questions that should be investigated by future research. First, it is unclear what specific aspects of parent-child media discussions are most effective in altering relationally 
aggressive media effects. The current study used a broad measure of active mediation by simply asking about the frequency of discussions about television and movie content. Different types of active mediation have been shown to have differential effects on violent media exposure (for a review, see Cantor \& Wilson, 2003). For example, negative comments about aggression by adults during viewing are more effective than neutral comments in decreasing children's acceptance of aggression (Corder-Bolz, 1980). Therefore, future research should investigate how variations in the content of parent-child discussions about relationally aggressive media may be related to effectiveness of such strategies in mitigating relationally aggressive media effects.

More detailed knowledge of what specific types of parent-child media discussions are predictive of relational aggression norms would also shed light on the mechanisms that account for the protective effects of parental mediation. Existing research and theoretical models have suggested that active mediation alters media effects through a variety of processes. Nathanson and colleagues (e.g., Nathanson \& Yang, 2003) suggest that parental mediation can increase children's negative evaluations of aggressive content, decrease the importance and relevance of aggressive media depictions, and/or decrease motivations to behave aggressively, by altering attitudes about aggressive behavior and the desire to imitate aggressive characters. Information about the specific mechanisms that account for the benefits of parental mediation of media on cognitions about relational aggression would be useful for the development of interventions aiming to reduce the negative effects of relationally aggressive media exposure.

Future research should also investigate child characteristics, such as age and gender, which may moderate the effectiveness of parental active mediation strategies. Although the current study controlled for gender and age effects, past research has noted gender differences in the effectiveness of such strategies with regards to mediation of violent media content. For 
example, Nathanson and Cantor (2000) found that active mediation while watching a violent cartoon reduced attitudes supportive of aggression among school-aged boys, but not among girls. There is also evidence that age moderates the effectiveness of active mediation strategies, with older school-aged children benefiting more from mediation than younger children (Corder-Bolz, 1980). Additionally, individual characteristics interact with type of mediation strategy, such that strategies have differential outcomes depending of the age and gender of the viewer. Nathanson and Yang (2003) found that mediation statements during viewing were most effective in reducing negative effects of aggressive media in children ages 5-8, whereas asking questions while viewing was the most effective mediation strategy for children ages 9-12. Studies that utilize samples of a variety of ages and also more closely examine gender will be useful in delineating the importance of child characteristics in altering the effectiveness of parental mediation strategies with regard to relationally aggressive media.

Finally, future research should investigate whether variations in the type of relationally aggressive media children are exposed to alter the relative importance of parental active mediation. For example, media researchers have labeled certain types of aggressive media portrayals as "high risk". Specifically, research indicates that exposure to rewarded media violence is associated with greater increases in aggressive behaviors and cognitions than exposure to punished media violence (e.g., Carnagey \& Anderson, 2005). Similarly, Linder and Gentile (2009) found that viewing rewarded relational aggression is associated with higher levels of teacher-reported relational aggression in fifth grade girls. It may be that parental active mediation is especially important (and effective) for children exposed to media that portrays relational aggression in a positive light, because these children are at greater risk of developing norms that are accepting of relational aggression as a result of their media exposure. 
There are several limitations of the current study. First, the sample, especially for the longitudinal analyses, was quite small; therefore, these findings should be viewed with caution, and replication of the current findings with a larger sample is needed. Second, reliance on child reports of both relational aggression media exposure and normative beliefs may have contributed to shared method variance. Perhaps children who have more accepting beliefs about relational aggression may be more sensitized to relational aggression in the media and therefore report higher levels of exposure. Future research would benefit from studies that utilize more objective ratings of the levels of relational aggression in the television programs and movies that children report viewing. Third, this study relied on child reports of aggressive media exposure. Although past research has shown that children are fairly accurate reporters of aggressive media content, future research should utilize more objective ratings. Finally, the direction of effects between relational aggression media exposure and norms about relational aggression cannot be determined from the current study. It may be that children seek out levels of relationally aggressive media content that are consistent with their normative beliefs about aggression.

Despite these limitations, the present study is an important first step in exploring mechanisms of relationally aggressive media effects and in investigating the role of parents in ameliorating these effects. The results of the current study indicate that relationally aggressive media exposure is associated with children's social cognitions about relational aggression. This is notable because beliefs and attitudes about aggression may be an important mediator of relationally aggressive media effects on behavior. Additionally, the current study suggests parental active mediation of media may attenuate these negative effects. Although many questions remain regarding parental active mediation of relationally aggressive media, these 
findings highlight the importance of pursuing this avenue of research for informing media literacy efforts. 


\section{References}

Anderson, C. A., \& Bushman, B. J. (2001). Effects of violent video games on aggressive behavior, aggressive cognition, aggressive affect, physiological arousal, and prosocial behavior: A meta-analytic review of the scientific literature. Psychological Science, 12(5), 353-359.

Anderson, C. A., \& Bushman, B. J. (2002). Human aggression. Annual Review of Psychology, $53,27-51$.

Anderson, C. A., \& Dill, K. E. (2000). Video games and aggressive thoughts, feelings, and behavior in the laboratory and in life. Journal of Personality and Social Psychology, 78(4), 772-790.

Anderson, C. A., Gentile, D. A., \& Buckley, K. E. (2007). Violent Video Game Effects on Children and Adolescents: Theory, Research, and Public Policy. New York: Oxford University Press.

Anderson, C. A., Shibuya, A., Ihori, N., Swing, E. L., Bushman, B. J., Sakamoto, A., Rothstein, H. R., \& Saleem, M. (2010). Violent video game effects on aggression, empathy, and prosocial behavior in Eastern and Western countries: A meta-analytic review. Psychological Bulletin, 136, 151-173.

Austin, E. W. (1993). Exploring the effects of active parental mediation of television content. Journal of Broadcasting \& Electronic Media, 37, 147-158.

Bandura, A. (1965). Influence of models' reinforcement contingencies on the acquisition of imitative responses. Journal of Personality and Social Psychology, 1, 589-595.

Bandura, A. (1986). Social foundations of thought and action: A social cognitive theory. Englewood Cliffs, NJ: Prentice Hall. 
Berkowitz, L. \& Powers, P.C. (1979). Effects of timing and justification of witnessed aggression on the observers' punitiveness. Journal of Research in Personality, 13, 71-80.

Buijzen, M., \& Valkenburg, P. M. (2005). Parental mediation of undesired advertising effects. Journal of Broadcasting \& Electronic Media, 49(2), 153-165.

Burks, V. S., Laird, R. D., Dodge, K. A., Pettit, G. S., \& Bates, J. E. (1999). Knowledge structures, social information processing, and children's aggressive behavior. Social Development, 8, 220-236.

Bushman, B. J., \& Huesmann, L. R. (2001). Effects of televised violence on aggression. In D. G. Singer \& J. L. Singer (Eds.), Handbook of children and the media (pp. 223-254). Thousand Oaks, CA: Sage.

Cantor, J., \& Wilson, B. J. (2003). Media and violence: Intervention strategies for reducing aggression. Media Psychology, 5, 363-403

Card, N. A., Stucky, B. D., Sawalani, G. M., \& Little, T. D. (2008). Direct and indirect aggression during childhood and adolescence: A meta-analytic review of gender differences, intercorrelations, and relations to maladjustment. Child Development, 79(5), 1185-1229. doi: CDEV1184 [pii] 10.1111/j.1467-8624.2008.01184.x

Carnagey, N. L., \& Anderson, C. A. (2005). The effects of reward and punishment in violent video games on aggressive affect, cognition, and behavior. Psychological Science, 16, 882-889.

Corder-Bolz, C. R. (1980). Mediation: The role of significant others. Journal of Communication, $30(3), 106-118$.

Coyne, S.M., \& Archer, J. (2004). Indirect aggression in the media: A content analysis of British television programs. Aggressive Behavior, 30, 254-271. 
Coyne, S.M., \& Archer, J. (2005). The relationship between indirect and physical aggression on television and in real life. Social Development, 14, 324-338.

Coyne, S.M., Archer, J., \& Eslea, M. (2004). Cruel intentions on television and in real life: Can viewing indirect aggression increase viewers' subsequent indirect aggression? Journal of Experimental Child Psychology, 88, 234-253.

Coyne, S. K., Linder, J. R., Nelson, D. A., \& Gentile, D. A. (in press) "Frenemies, Fraitors, and Mean-em-aitors": Priming effects of viewing physical and relational aggression in the media on women. Aggressive Behavior.

Coyne, S. M., Nelson, D. A., Graham-Kevan, N., Tew, E., Meng, K. N., \& Olsen, J. A. (2011). Media depictions of physical and relational aggression: Connections with aggression in young adults' romantic relationships. Aggressive Behavior, 37, 56-62.

Coyne, S.M., Nelson, D.A., Lawton, F., Haslam, S., Rooney, L., Titterington, L., et al. (2008). The effects of viewing physical and relational aggression in the media: Evidence for a cross-over effect. Journal of Experimental Social Psychology, 44, 1551-1554.

Coyne, S. M., Robinson, S. L., \& Nelson, D. A. (2010). Does reality backbite? Physical, verbal, and relational aggression in reality television programs. Journal of Broadcasting \& Electronic Media, 54, 282-298.

Coyne, S. M., \& Whitehead, E. (2008). Indirect aggression in animated Disney films. Journal of Communication, 58, 382-395.

Crick, N., \& Dodge, K. (1994). A review and reformulation of social information-processing mechanisms in children's social adjustment. Psychological Bulletin, 115, 74-74.

Crick, N. R., \& J. K. Grotpeter (1995). Relational aggression, gender, and social-psychological adjustment. Child Development, 66, 710-722. 
Gentile, D. A., Lynch, P. J., Linder, J. R., \& Walsh, D. A. (2004). The effects of violent video game habits on adolescent aggressive attitudes and behaviors. Journal of Adolescence, $27,5-22$.

Gentile, D. G., Coyne, S. C., \& Walsh, D. A. (2011). Media violence, physical aggression, and relational aggression in school age children: A short-term longitudinal study. Aggressive Behavior, 37, 193-206.

Gentile, D.A. \& Sesma, A. (2003). Developmental approaches to understanding media effects on individuals. In D.A. Gentile, (Ed.), Media violence and children (pp. 18-37). Westport, CT: Praeger.

Gerbner, G., Gross, L., Morgan, M., \& Signorielli, N. (1994). Growing up with television: The cultivation perspective. In J. Byrant \& D. Zillmann (Eds.), Media effects: Advances in theory and research (pp. 17-42). Hillsdale, NJ: Erlbaum.

Henry, D., Guerra, N., Huesmann, R., Tolan, P., Van Acker, R., \& Eron, L. (2000). Normative influences on aggression in urban elementary school classrooms. American Journal of Community Psychology, 28(1), 59-81. doi: 10.1023/a:1005142429725

Hogben, M. (1998). Factors moderating the effect of televised aggression on viewer behavior. Communication Research, 25, 220-247.

Huesmann, L. R. (1988). An information processing model for the development of aggression. Aggressive Behavior, 14(1), 13-24. doi: 10.1002/1098-2337(1988)14:1\&1t;13::AIDAB2480140104\&gt;3.0.CO;2-J

Huesmann, L. R., \& Guerra, N. G. (1997). Children's normative beliefs about aggression and aggressive behavior. Journal of Personality \& Social Psychology, 72(2), 408-419. doi: $10.1037 / 0022-3514.72 .2 .408$ 
Kirsh, S. J. (2010). Violent media part 2: Traditional screen media. In S. J. Kirsh, Media and Youth: A Developmental Perspective (pp. 213-232). Malden, MA: Wiley-Blackwell.

Linder, J.R., \& Gentile, D.A. (2009). Is the television rating system valid? Indirect, verbal, and physical aggression in programs viewed by fifth grade girls and associations with behavior. Journal of Applied Developmental Psychology, 30, 286-297.

Linder, J. R., \& Lyle, K. A. (2011). A content analysis of indirect, verbal, and physical aggression in television programs popular among school-aged girls. American Journal of Media Psychology, 4, 24-42.

Moller, I., Krahé, B., Busching, R., \& Krause, C. (2011). Efficacy of an intervention to reduce the use of media violence and aggression: An experimental evaluation with adolescents. Journal of Youth and Adolescence. Advance online publication. doi: 10.1007/s10964011-9654-6.

Muthén, L. K., \& Muthén, B. O. (1998-2007). Mplus user's guide (5th ed.). Los Angeles, CA: Author.

Murray, J. P. (2008). Media violence: The effects are both real and strong. American Behavioral Scientist, 51, 1212-1230.

Murray-Close, D., Crick, N. R., \& Galotti, K. M. (2006). Children's moral reasoning regarding physical and relational aggression. Social Development, 15(3), 345-372. doi: 10.1111/j.1467-9507.2006.00346.x

Nathanson, A. I. (1999). Identifying and explaining the relationship between parental mediation and children's aggression. Communication Research, 26, 124-143. 
Nathanson, A. I. (2001). Mediation of children's television viewing: Working toward conceptual clarity and common understanding. In W. B. Gudykunst (Ed), Communication Yearbook 25, (pp. 115-151). Mahwah, NJ: Lawrence Erlbaum.

Nathanson, A. I., \& Cantor, J. (2000). Reducing the aggression-promoting effect of violent cartoons by increasing children's fictional involvement with the victim: A study of active mediation. Journal of Broadcasting \& Electronic Media, 44, 125-142.

Nathanson, A. I., \& Yang, M. (2003). The effects of mediation content and form on children's responses to violent television. Human Communication Research, 29, 111-134.

Nix, R. L., Pinderhughes, E. E., Dodge, K. A., Bates, J. A., Pettit, G. S., \& McFadyen-Ketchum, S. (1999). The relation between mothers' hostile attribution tendencies and children's externalizing behavior problems: The mediating role of mothers' harsh disciplinary practices. Child Development, 70, 896-909.

Orobio de Castro, B., Veerman, J., Koops, W., Bosch, J., \& Monshouwer, H. (2002). Hostile attribution of intent and aggressive behavior: A meta analysis. Child Development, 73(3), 916-934.

Power, T.G. (2002). Parenting Dimensions Inventory—Short Version (PDI-S): A research manual. Unpublished manuscript, Washington State University.

Signorielli, N., \& Lears, M. (1992). Children, television, and conceptions about chores: Attitudes and behaviors. Sex Roles, 27, 157-170.

Slater, M.A., \& Power, T.G. (1987). Multidimensional assessment of parenting in single parent families. In J.P. Vincent (Ed.), Advances in family intervention, assessment, and theory. Vol. 4 (pp. 197-228). Greenwich, Conn.: JAI Press. 
Valkenburg, P. M., Krcmar, M., Peeters, A. L., \& Marseille, N. M. (1999). Developing a scale to assess three styles of television mediation: "Instructive mediation," "restrictive mediation," and "social coviewing." Journal of Broadcasting \& Electronic Media, 43(1), $52-66$.

Werner, N., \& Hill, L. (2010). Individual and peer group normative beliefs about relational aggression. Child Development, 81(3), 826-836.

Werner, N. E., Lyle, K., Eaton, A., \& Tseng, H. (2011). Mother-child discussions about peer conflict: A longitudinal study of maternal influences on preschooler's relational aggression. Manuscript under review.

Werner, N. E., \& Nixon, C. L. (2005). Normative beliefs and relational aggression: An investigation of the cognitive bases of adolescent aggressive behavior. Journal of Youth \& Adolescence, 34(3), 229-243. doi: 10.1007/s 10964-005-4306-3

Wilson, B.J., Donnerstein, E., Linz, D., Kunkel, D., Potter, J., Smith, S., Blumenthal, E., \& Gray, T. (1998). Content analysis of entertainment television: The importance of context. In J. T. Hamilton (Ed.),Television violence and public policy (pp. 13-53). Ann Arbor: University of Michigan Press.

Zelli, A., Dodge, K. A., Lochman, J. E., \& Laird, L. D. (1999). The distinction between beliefs legitimizing aggression and deviant processing of social cues. Testing measurement validity and the hypothesis that biased processing mediates the effects of beliefs on aggression. Journal of Personality and Social Psychology, 77, 150-166. 